\title{
TECHNOLOGICAL IMPROVEMENTS FOR THE CULTIVATION OF INVERTEBRATES AS FOOD FOR FISHES AND CRUSTACEANS.
}

\section{DEVICES AND METHODS}

\section{G. PERSOONE and P. SORGELOOS}

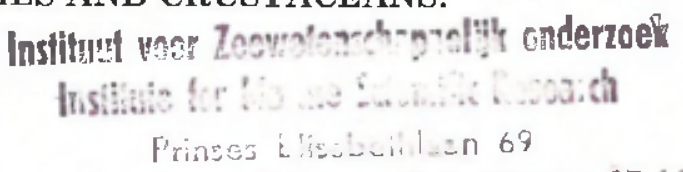

Laboratory for Biological Research in Environmental Pollufton, State University of Ghent, Ghent (Belgium)

(Received November 28th, 1974)

\section{ABSTRACT}

Persoone, G. and Sorgeloos, P., 1975. Technological improvements for the cultivation of invertebrates as food for fishes and crustaceans. I. Devices and Methods. Aquaculture, 6: $275-289$.

Technological problems can be considered as one of the bottlenecks of research concerned with culturing aquatic invertebrates in the laboratory, as well as at the pilot and mass production stages.

Oxygenation problems, circulation of the food and sedimentation problems can easily be solved by adapting the shape of the culturing vessels, i.e., by using funnel-shaped bottoms or high, narrow cylinders. In both cases, the food particles, settled on a very small bottom area, can easily be blown back into suspension using an air pump, which re-aerates the medium at the same time.

A number of culturing devices for different categories of organisms, including algae are described and commented on. The only power source involved is compressed air which aerates, keeps the water circulating, resuspends particles which have settled to the bottom and even provides $\mathrm{CO}_{2}$ in the case of algal culturing.

\section{INTRODUCTION}

"Developing mass rearing techniques for food organisms that are the right size and that are nutritious for larvae should be given high priority" (Houde, 1973).

The urgency of the subject dealt with in this paper is clear when one compares the large number of papers on the culturing of the desired end species, with the scarcity of information concerning culturing and culturing methods of live food for them. A visit to many mariculture farms, as well as to freshwater fish farms is all that is necessary to make one aware that the food problem is one of the major and more urgent ones to be solved. Quite often, if not always, this is either because it is hard to obtain the money for extensive fundamental studies on what can be called "intermediate steps" in mari- 
culture, or that scientists are unwilling to spend much time or effort in solving these apparently "secondary" problems.

Failure or difficulties in culturing these live food species is not even restricted to the field of "applied sciences". Indeed, in 1969, in the opening address of the International Symposium on "Cultivation of Marine Organisms and its Importance for Marine Biology" Kinne (1970) pointed out that less than $2 \%$ of all known marine organisms could be reared throughout their whole life cycle under controlled conditions, which of course results in "a severe bottleneck in the flow of information on life in the seas". In our opinion, both fundamental culture research in laboratories and extrapolation of the results to mass culturing, are slowed down by a lack of suitable techniques.

Too many scientists are still using conventional items such as beakers, flasks or aquaria, as the only culturing equipment in their experiments. They will invariably be confronted with three of the major difficulties in keeping organisms alive in a laboratory: (a) oxygenation problems; (b) circulation of the food; (c) sedimentation problems. We have been trying to overcome these problems in our laboratory for years, so we decided to adapt the shape of our culturing vessels to alleviate the aeration, circulation and suspension problems, instead of trying to solve them in conventional culturing jars, with the help of elaborate or cumbersome air-supplying or pumping devices.

With very few exceptions, all our culturing vessels have either funnelshaped bottoms or are high, narrow cylinders, both of which have a very small base area from which the sedimentated food particles are easily "blown back" into suspension by airbubbling.

A number of key rules should, in our opinion, always be observed in the elaboration of new devices or new research techniques on promising species:

(1) To oxygenate the medium without disturbing the animals.

(2) To keep the food in suspension so as to insure its optimum availability to the cultured species and to avoid sedimentation with subsequent bacterial development.

(3) To try to avoid complex (usually expersive) systems in which one of the numerous components may fail at any moment.

(4) To automate the technique as much as possible to reduce lahour.

(5) To use, whenever possible, inert sources of food to minimize the number of living links necessary to culture the desired species.

(6) To avoid laboratory systems and techniques which are clearly impossible to adapt to mass culturing purposes.

The application of these rules in our laboratory has led to the development of a certain number of devices and techniques. These we shall describe briefly together with some results.

\section{ALGAL CULTURING}

Although we have emphasized in "key rule 5" that one should avoid the 
use of live food as much as possible in culturing invertebrates, we partly agree with Taub (1971) that "... presently algal cultures provide the only practical method of mass feeding aquatic filter-feeders". Taub describes briefly the advantages of living algae as food but also points out that there are many disadvantages, among which is the need to culture large numbers of algae simultaneously with the filter feeders, if possible in the same facility or certainly near by. She emphasizes that there is always a risk of failure, more frequently due to mechanical causes than to biological ones. For certain filter feeders, however, (e.g., crustaceans, Brown, 1972; Sorgeloos, 1974) it has been proved that they can be successfully fed on frozen or dried algae; and this certainly solves a number of practical culturing problems. On the other hand, other larval organisms (e.g., mollusks) can only be reared on a diet of suitable live food.

Before discussing mass culture, we should like to mention briefly two small-scale culturing vessels which we use regularly; the first for fundamental studies (nutritional requirements or bioassays) on algae, and the second for culturing high density stocks (prior to mass cultures in large volumes).

The first device (Fig.1), a modification of the small tube with a sealed-in aeration tube mentioned by Venkataraman (1969), is simply a glass cylinder with a long funnel-shaped bottom, closed at the top by a rubber stopper with two holes. Through one of these holes, a small glass tube extends to the bottom of the cylinder; the outside end of this aeration tube is connected with an air supply, the inside end at the very bottom of the tube tapers to a capillary. Constant bubbling of air into this culturing vessel keeps the algal cells in suspension, provides them with the necessary $\mathrm{CO}_{2}$ and insures a constant contact with the nutrients. The advantages of this system over that described by Venkataraman are the following:

(1) Because the tube has an oblong funnel shape at the bottom, the air bubbling resuspends the algae more effectively.

(2) The independent air tube can easily be removed, cleaned, renewed and replaced.

The second device (Fig.2) is a classical glass serum bottle used daily in hospitals. It is hung upside down, with their normal iron wire clamps, in front of a bench of fluorescent tubes. Air is bubbled through a small piece of glass tube, fitting into the rubber stopper. The continuous supply of air from the bottom provides exactly the same advantages as in the culturing cylinder described above.

It is simple to sample small aliquots from these bottles while they are still hanging, by inserting the needle of a syringe through the rubber stopper and withdrawing the desired volume; it is easier still to slightly incline the hanging bottle until the outlet tube is submerged. The pressure inside due to the air being pumped in, will enable the suspension to flow down the air outlet tube, from which it can be collected.

It is worth mentioning that for several reasons, we do not work axenically even in the small $100 \mathrm{ml}$ cylinders: 

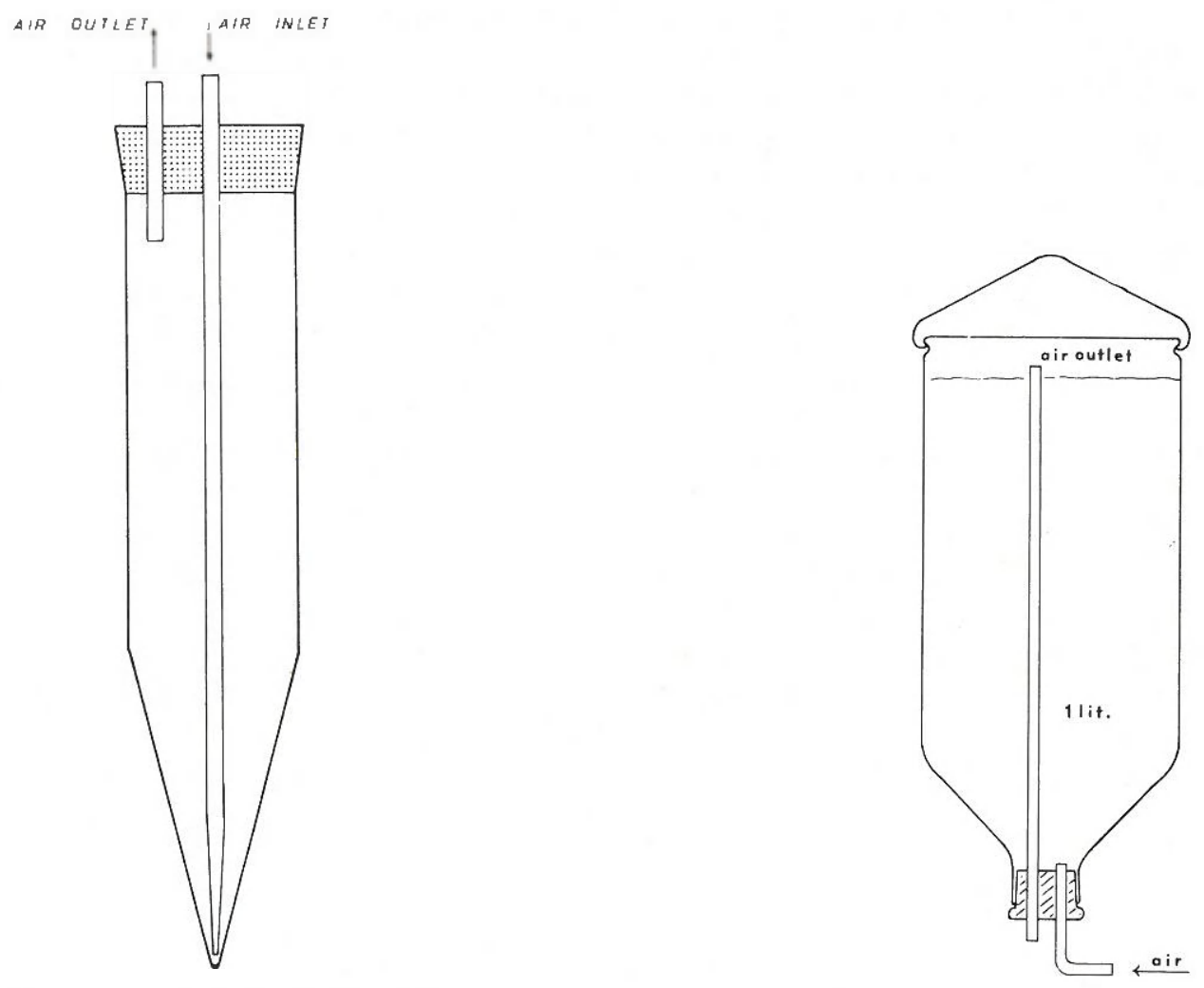

Fig. 1. 100-ml algal culturing tube.

Fig.2. Glass-serum bottle as used for culturing algae.

(1) As long as the algae are in the exponential phase of growth, the number of bacteria remains quite low. We have not yet had any serious contamination or toxicological problems caused by this accompanying microflora.

(2) Even when starting with axenic cultures, it is almost impossible, or at least very expensive and cumbersome, to take the necessary precautions to mass culture the algae in large volumes without bacterial contamination.

We never enrich the supplied air with extra $\mathrm{CO}_{2}$ as many researchers do. Experience has shown that even without this enrichment, algal growth is very fast and apparently not hampered by lack of $\mathrm{CO}_{2}$. Moreover, in high density cultures, photosynthesis seems to be limited more by the high optical density of the culture than by an insufficient supply of $\mathrm{CO}_{2}$.

The following species are regularly and successfully cultured in the two described devices: Phaeodactylum tricornutum, Dunaliella viridis, Nannochloris oculata, Tetraselmis suecica and Chlamydomonas coccoides. Species 
such as Monochrysis lutheri, Isochrysis galbana and Thalassiosira pseudonana could also be cultured quite easily. However, it always appeared that, although the food value of the latter was excellent, it was much more difficult to culture it regularly in large quantities without taking special care because the cultures are easily contaminated, either by other, less sensitive algae, by bacteria or protozoa.

The vats (Fig. 3) which we use for mass culturing purposes are transparent, very thin $(0.2 \mathrm{~mm})$ polyethylene cylinders with an inner diameter of approximately $15 \mathrm{~cm}$ and $2 \mathrm{~m}$ deep. The extremities of the plastic sheet are clamped to two short PVC cylinders of $1 \mathrm{~cm}$ thickness, the top one of which is open and the hottom one closed with a waterpro of PVC bottom. The culturing cylinder, with a volume of $30 \mathrm{l}$, is mounted vertically in a metal frame which bears two, three or four fluorescent tubes placed vertically at a distance of about $10 \mathrm{~cm}$ from the cylinder. Aeration is provided as usual, from the bottom. The system can be drained with a stopcock also mounted in the PVC bottom support. These $30 \mathrm{l}$ culturing columns can be considered as an enlarged but extremely cheap version of the "Algen Kultur Rohre" used by Von Witsch (1970) and co-workers in Germany for the cultivation of fresh-

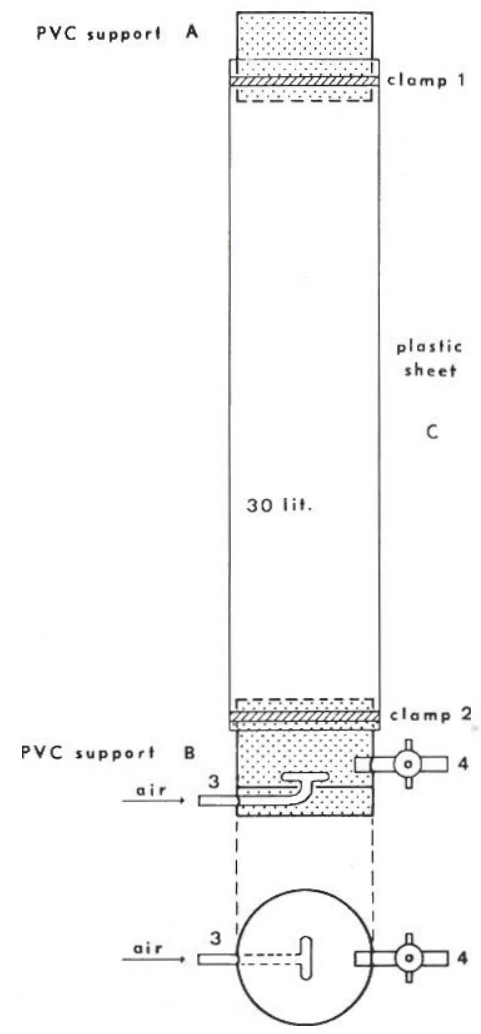

Fig. 3. 30-1 cylinders for mass culturing of algae. 
water algae. The disadvantage of the Algen Kultur Rohre, however, is that they are made of glass or transparent plastic material several $\mathrm{mm}$ thick (for example, Perspex), both of which are very expensive when compared to the few cents that the polyethylene sheets cost.

The advantages of vertical culturing columns compared to classical algal tanks with flat bottoms are quite numerous:

(1) No sedimentation of the algae.

(2) Steady circulation of the nutrients throughout the entire column and a continuous supply of $\mathrm{CO}_{2}$ present in the air.

(3) Much higher densities of algae than in conventional systems. Although the intense green colour of the algal cultures would normally slow down the photosynthesis considerably beyond a certain optical density due to lack of light, the steady movement of the algae by the air bubbling and the small diameter of the cylindrical culturing vessel insure a regular exposure to the lights closely surrounding the system.

(4) Through its vertical construction, the culturing column takes up little space (only 30 by $30 \mathrm{~cm}$ ), as compared to conventional systems which are mostly placed horizontally.

Last but not least, as has already been mentioned, the plastic sheets are not only very inexpensive but their replacement (maintenance) is very cheap, simple and quick.

Although we are quite aware of the fact that there are many suitable species which could be mass cultured in such $30 \mathrm{l}$ columns, till now we have used them a few times for the diatom Phaeodactylum tricornutum, but we daily culture the phytoflagellate Dunaliella viridis, which seems to be one of the easiest algae to mass culture and is at the same time an excellent food source for many aquatic herbivores. The diatom Phaeodactylum tricornutum reached a density of $18 \times 10^{6}$ cells $/ \mathrm{ml}$ in 14 days, from an initial density of $0.5 \times 10^{6}$ cells $/ \mathrm{ml}$. Cultures of the green alga Dunaliella viridis started with $0.2 \times 10^{6}$ cells $/ \mathrm{ml}$, attained $4.2 \times 10^{6}$ cells $/ \mathrm{ml}$ in a week and $7 \times 10^{6}$ cells $/$ $\mathrm{ml}$ in 12 days.

The culturing medium, with which we obtain excellent results, is a modification of that described by Walne (1956). His medium is modified by the addition of glycocol, a growth promoting amino acid.

$\begin{array}{ll}\text { Stock Solution } & \\ \mathrm{FeSO}_{4} \cdot 7 \mathrm{H}_{2} \mathrm{O} & 0.278 \mathrm{~g} \\ \mathrm{NaH}_{2} \mathrm{PO}_{4} \cdot 2 \mathrm{H}_{2} \mathrm{O} & 3 \mathrm{~g} \\ \mathrm{NaNO}_{3} & 30 \mathrm{~g} \\ \mathrm{MnCl}_{2} \cdot 4 \mathrm{H}_{2} \mathrm{O} & 0.47 \mathrm{~g} \\ \text { Glycocol } & 50 \mathrm{~g} \\ \text { Distilled water } & 1 \mathrm{l}\end{array}$

We usually distribute the stock in small quantities which are deep-frozen. The culture medium is made by diluting 1 part of the stock solution with 100 parts sea water. 


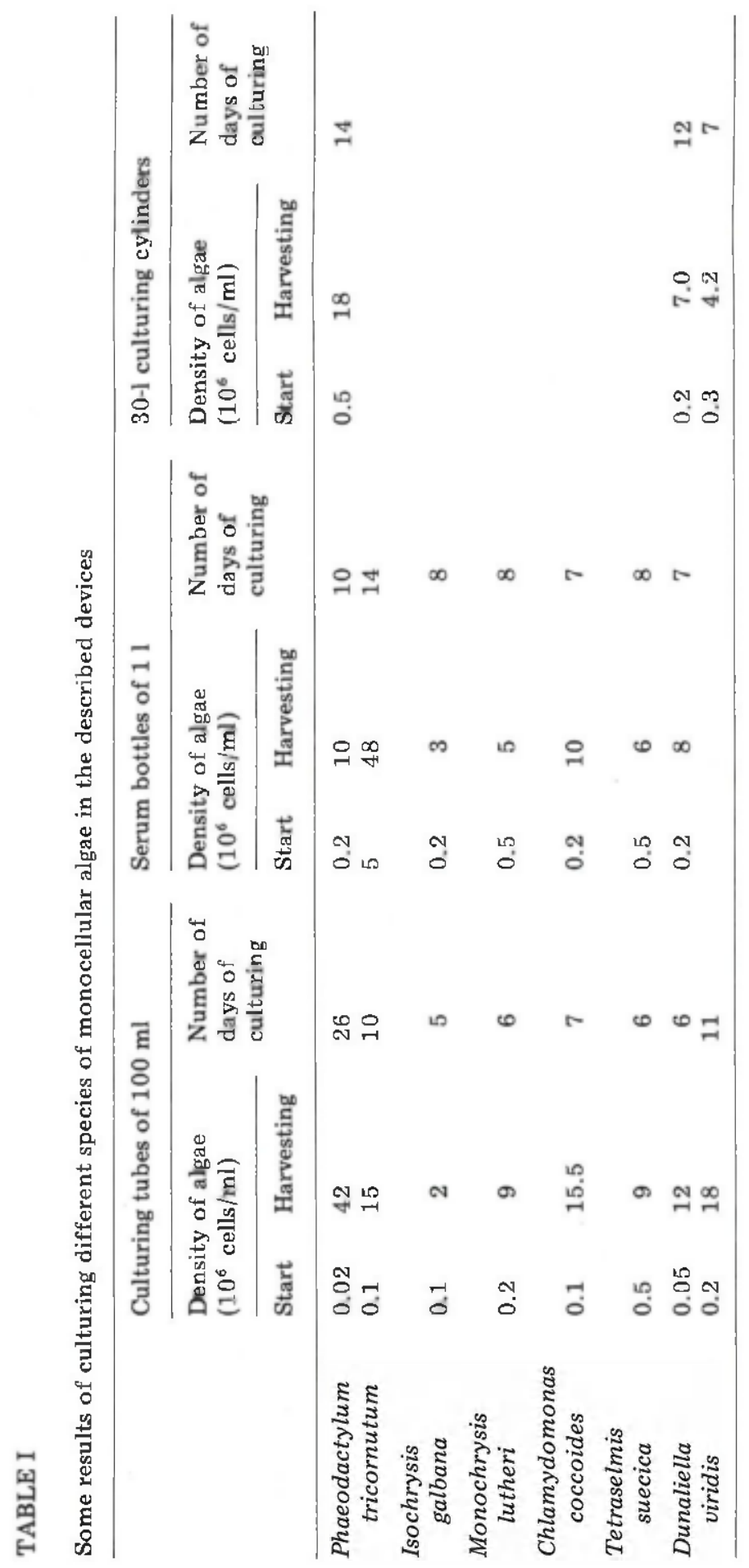


Table I gives some data about small-scale culturing of algae in the above mentioned medium, at a temperature of $22-23^{\circ} \mathrm{C}$, with continuous aeration and with the culturing devices placed about $10 \mathrm{~cm}$ from two 60 -watt fluorescent tubes. It should be emphasized, however, that the described algal medium, although excellent for mass culturing, does not fulfill the nutritional requirements of algae "in the long-run". We always keep the stocks in a more coinplete medium, namely, a mixture of the media described by Schreiber (1927), Walne (1956) and Provasoli et al. (1957).

\section{CULTURING OF INVERTEBRATES AND FISH LARVAE}

The best philosophy to start this part of our paper is undoubtedly that written by Rice and Williamson (1970) as one of the summarizing conclusions of their excellent paper on "Methods for rearing larval decapod crustacea".

“... No single rearing technique is suitaile for all species and all situations, the choice of technique in any particular case will, therefore, depend largely on the aim in view, whether it be taxonomic, physiological, behavioural, or commercial."

It is certainly beyond the scope of this publication, outlining our own culturing techniques, to compare them in detail with other existing devices and methods, many of which have proved to be excellent. Moreover, we should like to emphasize that, although we are using our equipment for culturing a restricted number of interesting species or groups of animals, there are many other possible uses for which the equipment might be interesting or convenient. As the following devices have been constructed for very different purposes, we shall comment on each of them separately, mentioning that the only relation between them are the first two of our "key rules" namely: aeration and circulation (of the medium) which in our systems are always achieved simultaneously by using compressed air.

\section{The flow-through column (Fig.4)}

This is an inexpensive laboratory-scale device suitable for culturing all kinds of organisms either immotile or motile but non-swimming. It has proved to be excellent for hatching out fish eggs and even for high density culturing of ciliates.

The system, conceived in 1972 (Mertens and Persoone), simply consists of piled up plastic petri dishes and a collecting - feeding vessel from which a classic air-water lifting tube raises the medium to the top of the column (Fig. 4 B). After it has passed through the system the water flows back to the collecting vessel (which can be filled with sea water, either with or without food particles). The peculiarity of this flow-through column is that the petri dishes are assembled in a particular way, i.e., by glueing the bottom part on to the lid (Fig. 4 A) creating what we call a "unit". These units can be piled at will, with possible removal of each unit and examination under a dissection 


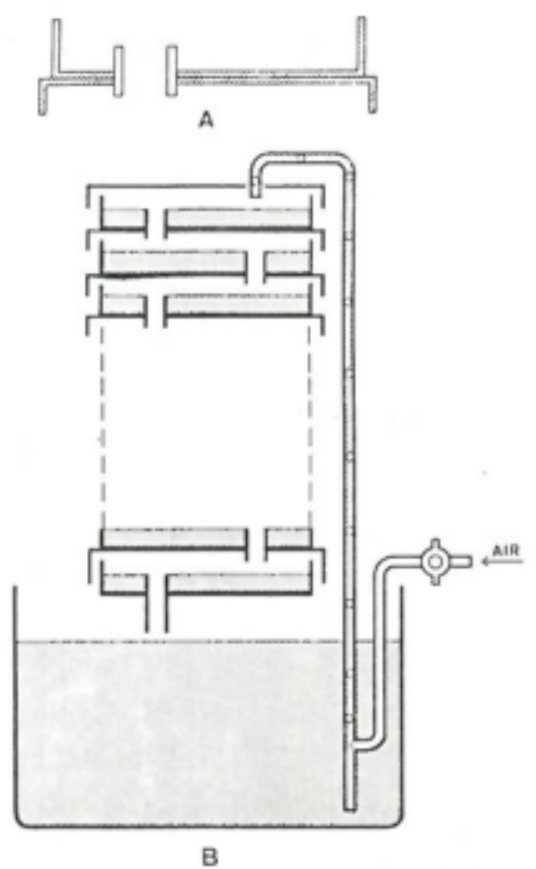

Fig.4. The flow-through column (from Mertens and Persoone, 1972): A, a single unit made with a petri dish; $\mathrm{B}$, the assembled flow-through column with its piled units, reservoir and air-water lift.

microscope without disturbing the organisms in the others. The water flow from each unit to the one beneath is insured by a small piece of plastic tubing glued into a hole drilled close to the wall of each unit. When the water has filled a unit to the level of the overflow tube, it will start to flow into the lower one, the splashing insuring a good re-oxygenation. Placing the units with the connecting holes diametrically opposed gives a gentle water current in each petri dish.

Although we are not working with decapod larvae, we suppose that it could be a useful and space-saving system to cultivate, e.g., cannibalistic species in large versions of such columns. Creeping or flowing of the animals from one unit to another can be prevented by covering the overflow tube with a gauze of appropriate mesh size.

\section{Simple culturing vessels for pelagic organisms}

The first culture vessel (Fig. 5 ) is simply a glass cylinder with a funnelshaped bottom connected to an air-water lifting tube which steadily circulates and aerates the medium. The idea of keeping the organisms in suspension in this way came from the well-known fact that vigorous air-bubbling in culturing systems (see, e.g., our algal culturing tubes) is deleterious to many 
organisms, especially larvae (Forster and Wickins, 1967; Greve, 1968; Rice and Williamson, 1970). The slow and gentle rise of the air bubbles in the air-water lift proved, on the contrary, to be harmless. Some algae even seemed to prefer such a circulation cylinder to the previously quoted culturing vessel with vigorous air-bubbling (cf part algae). Thalassiosira pseudonana, for example, could be cultured in such a culturing vessel very quickly in high densities, while it could not survive in our classical algal culturing tubes.

We shall comment further on the types of organisms for which this device is best suited. The cyclic falling of the organisms in the water droplets from the opening of the air - water lift onto the water surface is not ideal for very sensitive species. Therefore, we recently returned to the original algal culturing cylinder with aeration tube (Fig.1) as another possible culturing vessel for small aquatic invertebrates.

Instead of providing continuous and vigorous air-bubbling, we decided to try an intermittent, very gentle flow of air bubbles from the bottom, every half hour for about $15 \mathrm{sec}$, in order to insure the necessary re-oxygenation of the water, the resuspension of the fond particles and an even redistribution of the species in the culturing vessel. These tentative time lapses should of course be adjusted to each particular case by trial and error. Very sensitive freshwater rotifers without lorica, such as Epiphanes senta, could be cultured
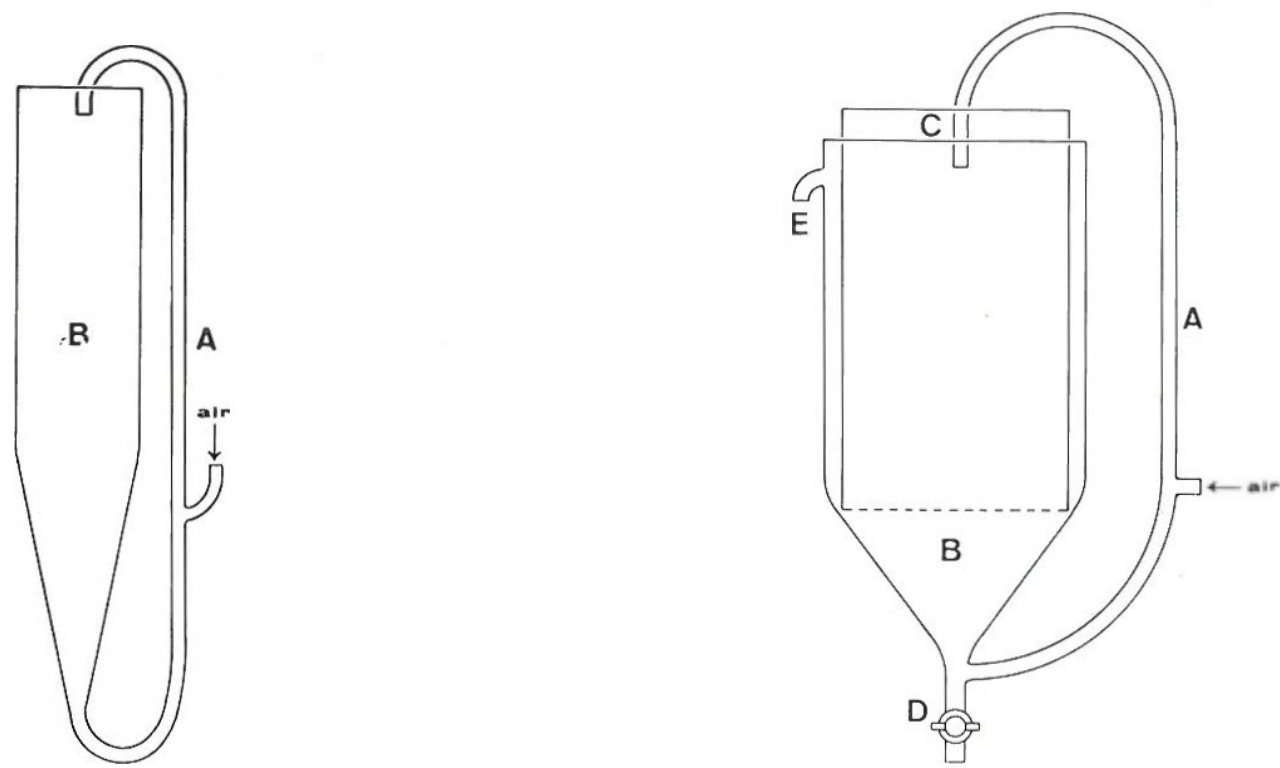

Fig.5. Culture vessel 1 (from Sorgeloos and Persoone, 1972): glass cylinder B with air water lift $\mathrm{A}$.

Fig.6. Culture vessel 2 (from Sorgeloos and Personne, 1972): culture vessel B with air water lift $\mathrm{A}$, removable internal basket $\mathrm{C}$, waste drain $\mathrm{D}$ and overflow $\mathrm{E}$. 
in this way in densities of more than $250 / \mathrm{ml}$ in $100 \mathrm{ml}$ tubes. Experiments in progress actually reveal that this figure can be improved upon. Moreover, results with other organisms such as crustaceans (copepods, cladocerans) indicated that the disturbance caused by short periods of aeration that were not too vigorous did not seem to harm the cultured species. The idea of a cyclic, very short remixing and aerating of the contents of the culture vessel by air bubbles, has gained our entire attention and is being used more and more both in laboratory-scale and mass culturing experiments. Nevertheless, in some cases, it is possible that even intermittent and gentle air-bubbling can disturb the cultured species either physiologically or ethologically. For these cases culture vessel 2 (Fig.6) is worth considering.

Culture vessel 2 is a broader version of culture vessel 1 with an internal removable cylinder, the bottom of which consists of a plankton gauze with a mesh small enough to keep the cultured species above the screen, but sufficiently large to let the food particles pass through. The improvement, compared to culture vessel 1 , is that the organisms are not carried into the air water lift tube, while the medium (containing the food) is steadily circulated and aerated. Thus the food steadily "passes the mouth" of the cultured animals, which, according to Shelbourne (in Costlow, 1969) appears to be of crucial importance for the successful rearing of many fish larvae.

Another advantage of this system is that the internal cylinder can be lifted out in one movement, thus collecting all the organisms on the gauze. As the animals grow, this cylinder can be replaced at will by another one with a gauze of larger mesh either to avoid its clogging or to feed the organisms with larger food particles. Last but not least, as well as food, fresh sea water can be added continuously, the lateral overflow insuring evacuation of excess water. The system really does meet the requirements of continuous culturing or long-term experiments.

We have developed a more sophisticated version of system 2 ; this has a lateral waste drain and a water collector with siphon (Fig.7). The waste drain has two stopcocks. With the top one (stopcock 1) closed any desired volume can be siphoned out of the culturing vessel through stopcock number 2 . With stopcock 1 open, only a limited volume of water will be siphoned out when opening stopcock 2 (i.e., that volume corresponding to the contents of the culturing vessel between water levels $a$ and $b$ ). The advantage of the second procedure is that foul water can regularly be drained off. This could be automated with an electro-magnetic valve commanded by a time switch.

The lateral water collecting tube with siphon from which the contents flow into the culturing vessel at regular intervals (instead of a continuous dropping of the medium from the air-water lift as in vessels 1 and 2) seems in many cases to be beneficial. Indeed, the sudden draining of a substantial volume of water into the culture vessel creates an upwelling current which sweeps the gauze bottom clean, a fact which is most important with regard to potential clogging or fouling of the latter. It also insures that the oxygenated water from the collector is more thoroughly mixed with the contents of the culture vessel. 


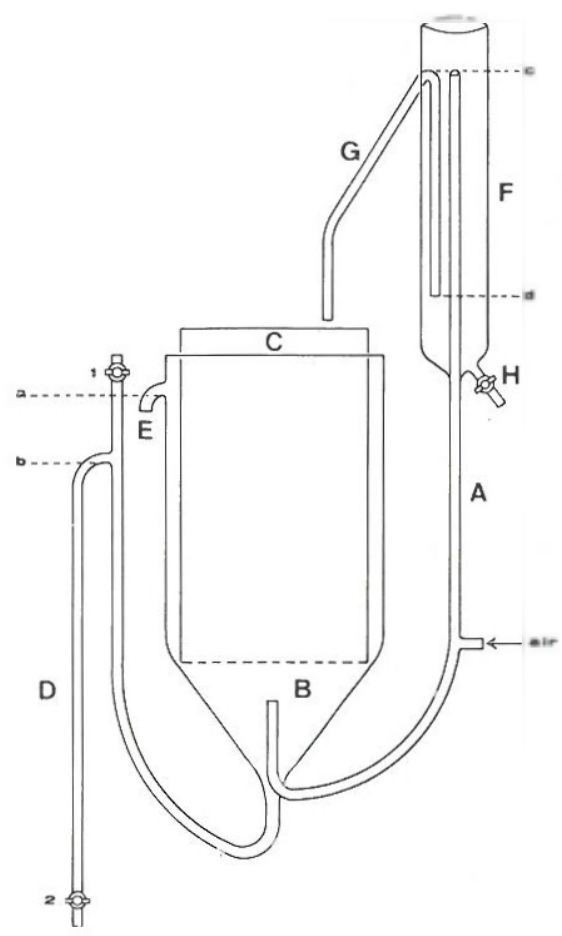

Fig.7. Culture vessel 3 (from Sorgeloos and Persoone, 1972): culture vessel 2 (see Fig.6), provided with a lateral waste drain $D$ and a water collector $F$ with siphon $G$.

As we have described these three culturing systems in detail (Sorgeloos and Persoone, 1972) we shall not enter here into the details of construction. Most parts of these devices are made of glass and polyethylene tubing.

Culture vessel 1 was well suited for high density culturing of pelagic organisms which are not too sensitive but are too small to be separated from the food particles by a screen, as in culturing vessel 2 and 3 . This is true for ciliates, rotifers, copepods and Artemia larvae.

Systems 2 and 3 seem to be very convenient for somewhat larger pelagic or benthic organisms which normally catch their food from the water. We obtained excellent results in culturing fish larvae and small fishes with both live food (ciliates, rotifers, Artemia larvae) and inert food particles.

We think that it would be very easy to construct large-scale versions of these systems for mass culturing purposes, although we have not yet attempted to do so.

\section{A culturing system with continuous separation of the progeny}

"For experimental research it is highly desirahle to have at one's disposal a flowthrough culturing system for adult organisms which is kept under controlled environ- 
mental conditions, and equipped with an automatic mechanism for continuous separation of the offspring" (Sorgeloos and Persoone, 1973).

Although we initially built this culturing system up for herbivorous crustaceans such as Artemia and Daphnia (Sorgeloos and Persoone, 1973), it can certainly be used in enlarged versions for many other herbivorous organisms or particle feeders, pelagic, as well as benthic ones (fish, crustaceans and molluscs). As usual the only power supply involved is compressed air which (as a good conductor) has many different functions: aeration, circulation, resuspension and even providing $\mathrm{CO}_{2}$ for algae in cases where herbivorous organisms are being fed. The apparatus (Fig.8) consists essentially of four

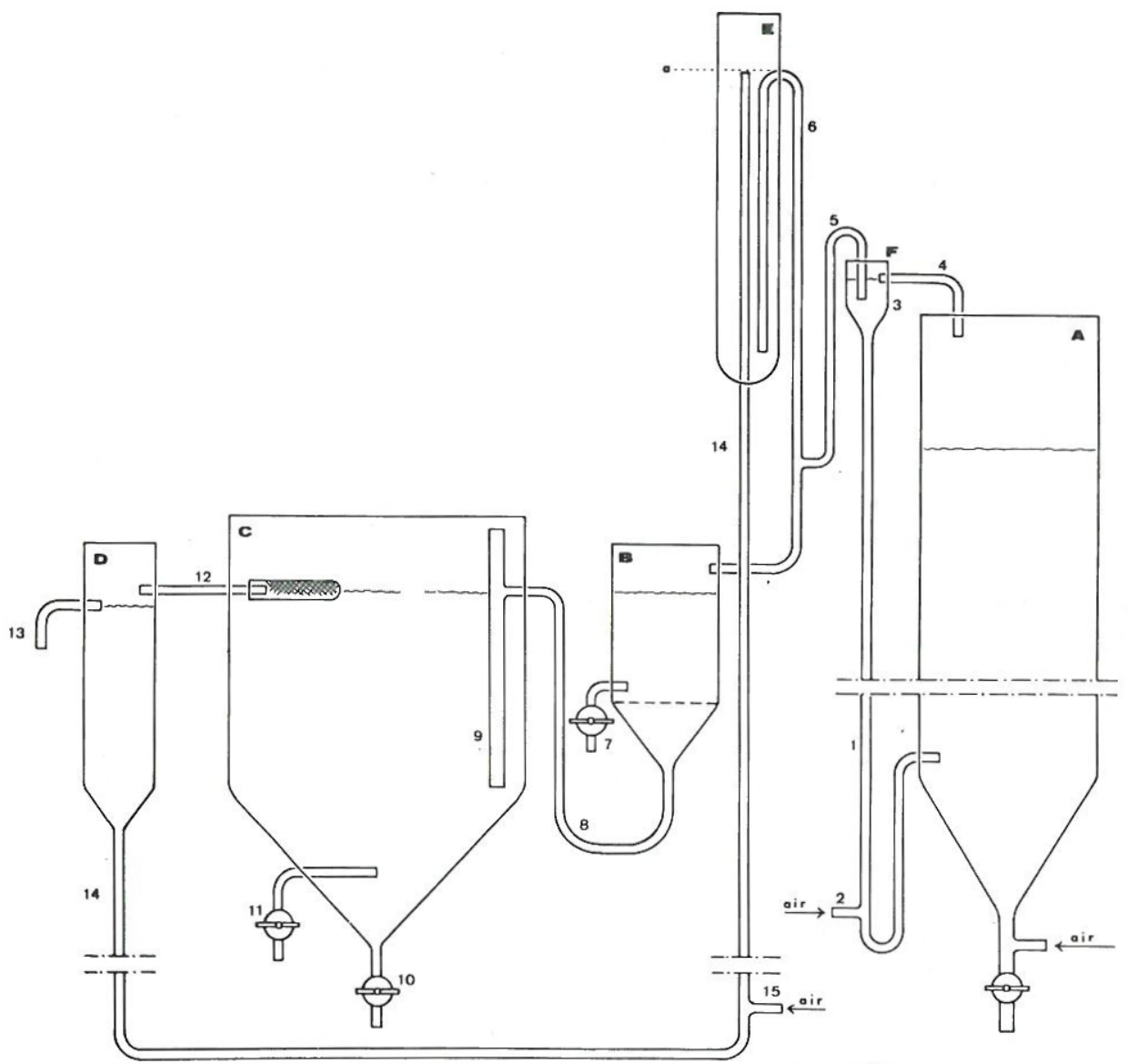

Fig.8. Culturing vessel with automatic separation of the progeny (from Sorgeloos and Persoone, 1973): A, algal culturing cylinder; B, adult rearing vessel connected to C; $\mathrm{C}$, larval collecting camber; $\mathrm{D}$, water supply cylinder connected to $\mathrm{E} ; \mathrm{E}$, water collector with siphon; $F$, food air - water lift system. 
transparent cylinders with funnel-shaped bottoms, a water collector and a food- air - water lifting system with terminal collecting vial and overflow. All these parts are connected by polyethylene tubing of various diameters.

Cylinder $A$ is the food vessel where the algae or inert food particles are kept in movement by steady aeration from the bottom. They are continuously raised by an air-water lift to vial F the excess flows from here back into the cylinder. Vessel B contains the adults. At the bottom is a gauze with a large enough mesh to allow the progeny to pass. The water collector $\mathrm{E}$ is either periodically or continuously filled by another air - water lift which drains water from cylinder D. When water siphoned from collector E starts to flow into culture vessel $B$, it creates lowpressure in vial $\mathrm{F}$ which also empties into cylinder $\mathrm{B}$ through siphon number 5 . Thus the adults receive food at regular intervals and at the same time there is a supply of oxygenated water. Since the water level in B will, momentarily, be higher than in cylinder $\mathrm{C}$ (with which $\mathrm{B}$ is connected by tube number 8 ) water will drain from vessel $\mathrm{B}$ to vessel $\mathrm{C}$ carrying the offspring through the gauze into cylinder $\mathrm{C}$. There can be a flow of water from the adult vessel to the progeny vessel every second or third minute, depending on the size of the water collector, insuring an automatic and complete separation of adults and juveniles, and excluding any possibility of ingestion of the latter by the former as is often encountered with many types of organisms. Thus the offspring can be harvested at will through stopcock 11 , situated close to the bottom of larval chamber D.

\section{ACKNOWLEDGEMENTS}

We are very indebted to Dr Ir E. Jaspers for her patient help in proofreading the manuscript. We are also indebted to the editors of Marine Biology, Archiv für Hydrobiologie and Biologisch Jaarboek Dodonaea for their permission to use some figures from our previous publications.

\section{REFERENCES}

Brown, A., 1972. Experimental techniques for preserving diatoms used as food for larval Penaeus aztecus. Proc. Natl. Shellfish. Assoc., 62: 21-25.

Costlow, J.D., 1969. Marine Biology. Proc. V Int. Interdisc. Conf. Gordon and Breach, N.Y., 606 pp.

Forster, J.R.M. and Wickins, J.F., 1967. Experiments in the culture of the prawn Palaemon serratus (Pennant). ICES-CM 1967-E13, Fisheries Improvement Comm., Conway, 8 pp.

Greve, W., 1968. The "Planktonkreisel", a new device for culturing zooplankton. Mar. Biol., 1: 201-203.

Houde, E.D., 1973. Some recent advances and unsolved problems in the culture of marine fish larvae. Proc. III Annu. Workshop World Mariculture Soc., 3: 83-112.

Kinne, O., 1970. International Symposium "Cultivation of marine organisms and its importance for marine biology". Opening address. Helgol. Wiss. Meeresunters., 20: 1-5.

Mertens, J. and Persoone, G., 1972. The flow-through column, a simple and multipurpose rearing device. Biol. Jaarb., 40: 271-275. 
Provasoli, L., McLaughin, J.J.A. and Droop, M.R., 1957. The development of artificial media for marine algae. Arch. Mikrobinl., 25: 392-428.

Rice, A.L., and Williamson, D.I., 1970. Methods for rearing larval decapod crustacea. Helgol. Wiss. Meeresunters., 20: 417-434.

Schreiber, E., 1927. Die Reinkultur von marinem Phytoplankton und deren Bedeutung für die Erforschung der Produktionsfähigkeit des Meereswassers. Wiss. Meeresunters., 16: $1-34$.

Sorgeloos, P., 1974. The influence of algal food preparation on its nutritional efficiency for Artemia salina L. larvae. Thalassia dugosl., in press.

Sorgeloos, P., and Persoone, G., 1972. Three simple culture devices for aquatic invertebrates and fish larvae with continuous recirculation of the medium. Mar. Biol., 15: $251-254$.

Sorgeloos, P., and Persoone, G., 1973. A culture system for Artemia, Daphnia, and other invertebrates, with continuous separation of the larvae. Arch. Hydrobiol., 72 : $133-138$.

Taub, F.B., 1971. Algal culture as a source of feed. Proc. I Annu. Workshop World Mariculture Soc., 1: 101-117.

Venkataraman, G.S., 1969. The cultivation of algae. Indian Counc. Agric. Res., New Delhi, 319 pp.

Von Witsch, H., 1970. Mikro- und Makroalgen als Nahrungsmittel. Ein Üherblick. Ber. Dtsch. Bot. Ges., 83: 519-526.

Walne, P.R., 1956. Experimental rearing of the larvae of Ostrea edulis L. in the laboratory. Fish. Invest. Lond., Ser. 2, 20: 1-23. 
